\title{
PANORAMA DEL CD-I Y DEL DVI
}

\author{
David Raitt*
}

Traducción del inglés: Tomás Baiget**

\begin{abstract}
Resumen: Se presentan nuevos sistemas digitales interactivos para PC, capaces de interaccionar textos, gráficos, imagenes video y sonido. El CD-I (Compact Disk Interactive), el DVI (Digital Vídeo Interactive) y la técnica de compresión de vídeo UVC. Todos ellos utilizan tecnología CD-ROM. Se of rece una panorámica de sus posibilidades, aplicaciones y empresas que los comercializan.

Palabras clave: Sistemas digitales interactivos, CD-I, DVI, UVC.
\end{abstract}

\begin{abstract}
Abetract: New interactive digital PC-based systems which can interact texts, graphics, tvimages, video and sound are presented. Among them CD-I (Compact Disk.Interactive), DVI (Digital Video Interactive) and UVC video compression. All of them exploit CDROM technology. An overview of its possibilities, applications and enterprises which develop them is offered.

Keywords: Interactive Digital Systems, CD-I, DVI, UVC.
\end{abstract}

\section{Introducción}

El término multimedios significa la integración de texto, sonido e imágenes, estáticas y en movimiento, en el mismo soporte o medio. Ejemplos son la televisión, el videocasete, el videodisco, etc. Sin embargo, estos sistemas son inflexibles, ya que el usuario no puede participar, de forma realmente activa, en el proceso de recuperación de la información, pues, aunque pueda parecerlo en algún caso (por ejemplo, el videodisco), está obligado a ir donde el programa le lleve.

La necesidad de sistemas digitales para PC que fueran interactivos y pudieran reproducir imágenes y sonidos, y que además fueran capaces de interaccionar con gráficos producidos en el microordenador, ha dado lugar al desarrollo de nuevas tecnologías. Entre ellas están el CD-I (Compact Disk-Interactive) y el DVI (Digital Video Interactive). Ambas utilizan la tecnología del CD-ROM. A continuación se presenta un panorama de éstas y otras tecnologías y aplicaciones, así como una bibliografía básica que confiamos dará al lector conocimiento de este mundo fascinante que acaba de empezar. Se observará que no se intenta abarcar la tecnologia del videodisco, y ello se debe a dos razones. En primer lugar, no se trata de una nueva tecnología, sino de una ya muy establecida. En segundo lugar, es analógica y no digital, y como tal, menos flexible. Por otro lado, es necesario mencionar el MediaMaker de la BBC Interactive Televisión Unit, el cual, usando un Macintosh, es capaz de controlar fuentes como videodiscos, videocasetes y discos compactos, permitiendo autoeditar vídeo en casa.

* Editor: The Electronic Library; ** Institut d'Estadistica de Catalunya, Barcelona.

Recibido 23-11-89 


\section{Disco Compacto Interactivo (CD-I)}

Ver algunas fotos de las Islas Canarias y seleccionar el comentario turistico en japonés; escoger una melodía de los Dire Straits y reproducirla mientras se lee la letra en la pantalla, divertir a los niños con unos dibujos animados o dejarles ver un vídeo de osos polares haciendo piruetas en el agua; adquirir conocimiento sobre Van Gogh al tiempo que se ve una selección de sus pinturas; hojear un glosario de términos; borrar las imágenes en sentido vertical y horizontal, mezclarlas, o dividir la pantalla en cuatro partes. Todas estas cosas, y más, las realiza el disco prototipo CD-I.

El CD-I es el primer medio de publicación que hace llegar el mundo de los multimedios (integración de texto, gráficos, imágenes, vídeo y sonido) al gran público. Philips y Sony han desarrollado las normas para la construcción de CD-I, que quedan recogidas en el llamado "Libro Verde". Dichas normas hacen uso de la tecnología óptica y son resultado de la evolución tanto del CD-ROM como del CD-V. Debido a que el CD-I es al mismo tiempo un ordenador (aunque dicho término no debe entenderse como ordenador personal en su sentido usual) y una televisión (el CD-I puede ajustarse a todas las normas de televisión), los usuarios pueden tener lo mejor de ambos mundos y controlar realmente la acción o situaciones dinámicas en tiempo real, mezclándolas y compaginándolas según deseen.

El CD-I of rece una amplia variedad de posibilidades y operaciones adicionales que incluyen sonido mono y estéreo; efectos visuales (desplazamientos de imágenes, cortes, borrados y fundidos); gráficos en tres dimensiones; imágenes fijas y en movimiento; cinco niveles diferentes de reproducción de sonido (digital, alta fidelidad, media fidelidad, voz y voz sintetizada); tres grados de resolución de imágenes; cuatro planos separados de imagen con o sin transparencia; y cuatro técnicas de codificación para imágenes fotográficas, textos y gráficos, dibujos animados y color. Los dibujos animados en pantalla completa eran ya posibles desde el principio del CD-I, pero sólo recientemente se ha ampliado el canal de datos lo suficiente como para poder tener imágenes de vídeo en pantalla completa.

Aunque el CD-I ya está normalizado, se venderá inicialmente como un sistema independiente y autosuficiente de vídeo interactivo, fabricado especialmente para este propósito (aunque puedan aprovecharse las pantallas de TV convencionales). Los componentes del sistema son: un lector de CD-I, un controlador de multimedios (que controla las entradas del usuario, la salida digital, el disco CD-I y el "software" de aplicación), un mando a distancia (aunque también puede usarse un ratón), una tarjeta de memoria, y un módulo opcional de expansión para mejorar la operación. Se espera que el sistema cueste alrededor de 1.000 dólares (unas 120.000 pesetas).

Como los discos del CD-I son los mismos que los del CD-ROM, pueden contener hasta $650 \mathrm{Mb}$, equivalentes, según la información que se grabe, a 8.000 fotos fijas, hasta 20 horas de sonido (dependiendo del nivel de calidad, por ejemplo, dos horas de música de alta fidelidad o 17 horas de narración), 300.000 páginas de texto, 60.000 gráficos o 150.000 páginas de textos y gráficos, los programas almacenables en 1.000 discos flexibles de ordenador, 0 unos cinco minutos de imágenes de vídeo en pantalla parcial. Y toda esta información puede combinarse e integrarse, resultando, por ejemplo, en imágenes con textos explicativos, música y voz (texto y voz pueden corres- 
ponder a lenguas diferentes). Existe la posibilidad de almacenar hasta ocho idiomas diferentes (en voz), lo que ocuparia, aproximadamente, la mitad de la capacidad del sistema, dejando el resto para el almacenamiento de imágenes.

Aun sufriendo un retraso de dos años respecto a lo que se había anunciado, el CD-I pretende ser el primer y mejor producto para el mercado de consumo. Tendrá aplicaciones en el campo educativo (estudio en casa, libros de referencia, formación interactiva, DIY, libros hablados); ocio (música, juegos, simulaciones, vídeo); ocio creativo (dibujo y pintura, cine, edición de video, composición); trabajo (recuperación de información, tratamiento de documentos, programación, creación de bases de datos), y el hogar (telecompra, telebanco, compra de terrenos, viajes, deportes, jardineria, cocina, fotografia). Es decir, cualquier tema en el que el usuario pueda interaccionar y aprender a través de imágenes y sonido. Aunque ya se están vendiendo los primeros equipos CD-I, aún hay pocos discos CD-ROM disponibles para equipos CDI. Aparte del disco de demostración, hay uno llamado "Tell me why" (Dime por qué), dirigido a niños pequeños, que abarca cinco temas: el mundo, el cuerpo, el origen de las cosas, cómo funcionan éstas y el zoo. Se están preparando otros discos, pero se desconoce cuándo estarán en el mercado.

\section{CD-ROM XA}

Para salvar el vacio entre el CD-ROM (un periférico de ordenador) y el CD-I (un sistema autónomo y autosuficiente), y de cara al mercado profesional, Philips, Sony y Microsoft han anunciado un nuevo formato de CD-ROM llamado CD-ROM XA (Extended Architecture) que incorporará tecnología de gráficos y sonido del formato CD-I. Al tiempo que of rece funciones similares a las del CD-I (sonido de alta fidelidad acompañando a lo que aparece en pantalla, por ejemplo) tiene la ventaja de no depender de un tipo de sistema operativo o procesador como ocurre con el CD-I. Esto significa que los editores pueden producir discos reproducibles tanto en equipos para ordenadores personales como en equipos para CD-I. Esta tecnología ha sido adaptada también por Intel e IBM, y parece que no encarecerá demasiado el coste de un lector normal de CD-ROM. Ya se ha anunciado la disponibilidad de los primeros equipos $\mathrm{XA}$.

\section{Vídeo Digital Interactivo (DVI)}

El DVI (Digital Video Interactive) ha sido desarrollado por el Centro David Sarnoff de la RCA, y posteriormente vendido a Intel. A diferencia del CDI, el DVI es una tecnologia más que un sistema completo y autosuficiente integrado en un solo equipo. Está compuesto por cuatro elementos: un conjunto de chips VLSI (Very Large Scale Integration) diseñados a medida, y que es la base del sistema de video; una especificación para la interfase del sof tware; formato de ficheros de datos audio/vídeo; y algoritmos de comprensión/descompresión que permiten el almacenamiento de 72 minutos de vídeo en CDROM para su descompresión en tiempo real. Con estos elementos se puede desarrollar DVI con las tres facetas interconectadas (vídeo, sonido y almacenamiento de datos en CD-ROM) en cualquier microordenador de 16 bits (IBM va a incorporar chips DVI en su serie de ordenadores personales). El 
DVI se asemeja al CD-I en cuanto a que utiliza CD-ROM como medio de almacenamiento, y permite a los usuarios manipular una gran variedad de imágenes de multimedios y programar con palanca de mando o ratón. Sin embargo, y a diferencia del CD-I, el DVI no se ha diseñado exclusivamente para ser usado con CD-ROM, sino que puede usar discos duros y otros tipos y tamaños de discos, incluidos los WORM. Una desventaja es que, de momento, solamente Intel puede hacer la compresión necesaria de los datos del usuario, y, desde luego, se requiere un sistema DVI para decodificar discos.

Entre las posibilidades que of rece el DVI están: video sintetizado -con textura fotográfica- a partir de objetos de dos y tres dimensiones; imágenes fijas de alta resolución; gráficos de alta velocidad, panoramas de 360 grados; y múltiples series de video, texto y sonido mezcladas interactivamente. Esto significa que, por ejemplo, un disco puede contener 20 minutos de imágenes en movimiento con 7 horas de voz y 5.000 fotografías de alta resolución. Del mismo modo, puede contener 20 minutos de vídeo, 1.000 imágenes fijas acompañadas cada una de un minuto de sonido, más 50.000 páginas de texto. Integrando imágenes de alta resolución, gráficos de alta velocidad, animación en tres dimensiones, sonido de alta calidad y texto en pantalla completa, los usuarios pueden manipular la información y las escenas, desplazarse en cualquier dirección, hacer zooms, superponer colores, participando así, de forma activa, en lo que ocurre en pantalla. Una de las primeras demostraciones que se han realizado es un viaje a las ruinas mayas de Palenque. Utilizando una palanca de mando, el usuario puede merodear por las ruinas (aunque un poco a trompicones), detenerse donde lo desee y mirar alrededor, y penetrar en los lugares escogidos para conseguir más información.

Aunque el CD-ROM puede almacenar unos $650 \mathrm{Mb}$ de información, la capacidad de almacenamiento del vídeo digital es sólo de unos 30 segundos, información que tarda en visualizarse más de una hora (debido a la velocidad normal de salida de los CD-ROMs). El DVI salva este problema comprimiento el sonido e imágenes digitales antes de hacer el disco maestro. Dicho proceso requiere ordenadores de capacidad considerable, y no se realiza, normalmente, en tiempo real. Sin embargo, cuando las imágenes y el sonido comprimidos se recuperan, la descompresión se realiza en tiempo real para reproducir la calidad original de sonido e imágenes, siendo posible reproducir estas últimas a la velocidad normal de video de 30 imágenes por segundo. De esta forma, un disco CD-ROM puede almacenar más de una hora de video en pantalla completa, con sonido estéreo de alta calidad, o, proporcionalmente, cuatro horas de video si la imagen ocupa sólo un cuarto de la pantalla.

Al igual que el CD-I, el DVI está pensado para el mercado de consumo, concretamente, educación, ocio, y recuperación y suministro de información. Pero también se dirige a los mercados industrial, de negocios y profesional en los que se necesiten programas de formación que incluyan simulaciones y secuencias de vídeo. Además, el DVI es útil en diseño asistido por ordenador (CAD) donde se requieren cambios instantáneos de situación, perspectiva, color, forma y textura. Por ejemplo, en diseño arquitectónico y de interiores, diseño de decorados teatrales, educación, viajes y exploraciones, paisajismo, moda, y simulación de vuelo o de cualquier otro tipo. El coste actual se eleva a 7.000 dólares (unas 840.000 pesetas), pero en un futuro se espera un coste considerablemente menor (alrededor de 500 dólares, unas 60.000 pesetas) de productos DVI basados en chips de segunda generación. El acuerdo de IBM 
con Intel parece interesante para ambas partes: está previsto comercializar la colección de tarjetas con conectores hacia mediados de 1989 en ordenadores compatibles IBM PC/AT, conocidos como "Pro 750 Application Development Platform", y para 1990 se espera un controlador de tarjeta única con chips ya de serie.

\section{Compresión de vídeo UVC}

Mientras que, tanto el CD-I como el DVI tienen sus partidarios y detractores, la prensa técnica parece bastante unánime en mostrar aprobación y gran interés por una tecnología nueva y barata de compresión de vídeo desarrollada por UVC Corp., que se convierte en competidora potencial del DVI. UVC Corp. ha desarrollado un algoritmo para tele-vídeo (vídeo-conferencias, correo de video, bases de datos en vídeo) que graba en tiempo real. Mientras que el DVI necesita unos 90 minutos de tiempo de compresión para cada minuto de vídeo, el sistema UVC invierte tan sólo un minuto. En un CD-ROM es posible almacenar hasta tres horas de video, frente a una hora que permite el DVI. El sistema of rece tamaño de pantalla variable, resolución, fidelidad, movimiento y velocidad de grabación variable. Asimismo, mientras el DVI produce vídeo para 30 imágenes por segundo, el sistema UVC se ha diseñado para 10 imágenes por segundo. Si se ajusta bien la diacronización, el usuario no percibe la diferencia.

Las tarjetas de compresión y de gráficos se pueden integrar fácilmente en los ordenadores personales de los usuarios, aunque UVC ha desarrollado su propio sistema: el VP-2000 -un ordenador personal de uso general que se puede configurar de diferentes formas para capturar, visualizar, transmitir y recibir video con cualquier grado de movimiento-. El VP-2000 es el primer producto capaz de proporcionar video-conferencia en tiempo real, o capturar, almacenar y catalogar imágenes fijas o con movimiento en un disco duro de un ordenador personal. En $380 \mathrm{Mb}$ se pueden almacenar unos 45 minutos de vídeo. El VP-2000 puede también enviar vídeo de un lugar a otro a través de cualquier medio de comunicación, incluyendo las lineas telefónicas normales.

\section{Conclusión}

A pesar de que los videodiscos interactivos están en el mercado desde hace tiempo, y que los CD-ROM están de moda, ambos son causa de confusión. De hecho, los mutimedios están en los inicios de su desarrollo, y no se encuentran exactamente definidos. No se trata de un problema tecnológico, ni de escasez de profesionales creativos o aplicaciones adecuadas, sino de un problema económico: crear sistemas de multimedios (especialmente vídeo) que informen, instruyan o entretengan, cuesta una fortuna. Por otro aldo, la gente no está dispuesta a invertir dinero en el desarrollo de un disco cuando su tecnología se halla en continua y rápida evolución.

Cuando se disponga de discos CD-I realmente asequibles, los usuarios de bibliotecas podrán disponer de ellos, como ocurre actualmente con discos, cintas de vídeo o cualquier otro material AV.

Puesto que una biblioteca o centro de información puede hacer que los equipos y discos DVI sean accesibles a los usuarios, no hay razón para que 
no utilicen dichos medios para desarrollar sus propios escenarios de formación, tanto para los usuarios como para el personal, y para organizar visitas dirigidas a la propia biblioteca. El usuario podría elegir su propia ruta y seleccionar libros, revistas y otro material por el camino, siendo posible recibir explicaciones en varios idiomas. Dichos sistemas, con un software adecuado, podrían usarse también para diseño de bibliotecas, pudiéndose ver instantáneamente los resultados de los proyectos a todo color. Otros beneficiarios serían aquellas bibliotecas que disponen de fotografías, recortes de prensa, mapas, carteles, etc. Dichas colecciones pueden intercalarse con comentarios y vídeos. Los bibliotecarios y expertos en información pueden soñar ahora nuevas aplicaciones para sus organizaciones: bases de datos de diseños en vídeo, anuncios, rostros de personas, coches o aviones en movimiento usados como una herramienta de mercado. Las aplicaciones son prácticamente ilimitadas. Tenemos ante nosotros un futuro realmente fascinante.

Para más información acerca de los desarrollos expuestos, contactar con:

Intel Corporation (DVI Technology), CN 5325, Princeton, NJ 08543-5325, USA. Tel. +1 (609) 7342211.

Philips New Media Projects Ltd, 12 Oval Road, London NW1 7DH, England, Tel. +44-(0)1 4825258.

UVC Corp., 16800 Aston Street, Irvine, CA 92714, USA. Tel. +1 (714) 2615336 . Fax +1 (714) 2611677.

\section{Bibliografía}

1. DESMARAIS, N CD-I v8. DVI. CD-ROM Librarian, 4 (3), 24-28, March 1989.

2. DIXON, D.F. Life before the chips: simulating digital video interactive technology. Communications of the ACM, 32 (7), 824-831, July 1989.

3. FOTI, L. CD-I: a Focal Technology. CD-ROM Librarian, 3 (5), 21-24, May 1988.

4. FRENKEL, K.A. The next generation of interactive technologies. Communications of the ACM, 32 (7), 872-881, July 1989 (Includes CD-I and DVI).

5. GLASS, L.B. Digital Video Interactive. Byte, 14 (5), 283-289, May 1989.

6. HERMAN, G. CD-I: a new solution looking for the problem. InterMedia, 17 (1), 35-39, Jan 1989.

7. HERTHER, N.K. DVI: Combining Text, Audio, Graphics and Full-Motion Video on a Silver Disk - an Interview with Art Kaiman. LaserDisk Professional, 1 (4), 29-37, Nov 1988.

8. HERTHER, N.K. DVI is moving closer to the marketplace. Online, 13 (2), 107-109, March 1989.

9. An introduction to CD-ROM XA. Microsoft, 1989.

10. ISMAIL, R. Creative CD-I authoring. In: Proceedings of Optical Info'89, 18-20 April 1989, Amsterdam, The Netherlands. Learned Information, 137-143, 1989.

11. LAMBERT, S.; SALLIS, J. CD-I and Interactive Videodisc Technology. Sams, 1986.

12. LAVALEE, D.A. Compact Disc-Interactive: mew media in electronic publishing. Sun Technology, 2 (2), Spring 78-83, 1989.

13. LUTHER, A.C. Digital Video in the PC Environmet. McGraw-Hill, 1989. (Features DVI technology).

14. LUTHER, A.C. You are there... and in control. IEEE Spectrum 25 (9), 45-50, Sept 1988. (DVI tecnology).

15. MORRIS, S. Digital Video Interactive - a New Integrated Format for Multi-Media Information. Microcomputers for Information Manazement, 4 (4), 249-261, Dec 1987.

16. PRESTON, J.M. Compact Disc-Interactive: a Designer's Overview. Kluwer, 1988.

17. RIPLEY, G.D. DVI - a digital multimedia technology. Communications of the ACM, 32 (7), 811-822, July 1989.

18. TEIXEIRA, K.; SULlivaN, M. Computer graphics' new look. IEEE Potentials 8 (2), 32 -34, May 1989. (DVI tecnology).

19. TINKER, M. DVI parallel image compression. Communications of the ACM, 32 (7), 844-851, July 1989.

20. WHITE, M.S.; ROSEN, D. Technology and applications of compact-disk interactive. In Oppenheim, C. CD-ROM: fundamentals to applications. Butterworths, 142-154, 1988. 